\title{
Diabetic retinopathy in Cushing's disease
}

\author{
J. CASSAR \\ M.D., M.R.C.P.
}

\author{
EVA M. KOHNER \\ M.D., F.R.C.P.
}

\author{
G. F. JoPLIN \\ Ph.D., F.R.C.P.
}

The Department of Medicine, Royal Postgraduate Medical School, Hammersmith Hospital, London W12 OHS

\begin{abstract}
Summary
A patient with proliferative diabetic retinopathy in long-standing Cushing's disease is described.

\section{Introduction}

Most cases of Cushing's syndrome are known to have abnormalities of carbohydrate metabolism (Plotz, Knowlton and Ragan, 1952; Thorn, Renold and Cahill, 1959) and between $10-25 \%$ of patients have clinical diabetes mellitus (Thorn et al., 1959). However, the vascular complications of diabetes are reported to be uncommon (Thorn et al., 1959). In the past, adrenalectomy was tried for relieving diabetic retinopathy, but although a few cases had some regression (Malins, 1962; Graef and Maier, 1962) poor results led to abandonment of the procedure. The authors now report what they believe is the first case of proliferative diabetic retinopathy in Cushing's disease.
\end{abstract}

\section{Case report}

The patient, now aged 54 years, had gangrene of the scrotum in 1970; glycosuria was found but not followed-up. In 1975, after his complaining of weakness, his general practitioner detected glycosuria. Diabetes mellitus was diagnosed at the local hospital and he was put on tolbutamide $500 \mathrm{mg}$ thrice/day on which he continued for most of the time. He then noticed muscle weakness and was noted to have hypertension. Cushing's syndrome was suspected and he was referred to a hospital in London where the typical features of Cushing's syndrome were noted. His BP was $180 / 100 \mathrm{mmHg}$, he had proliferative retinopathy in the right eye, marked proximal muscle weakness and peripheral neuropathy.

Investigations gave the following results, normal values in parentheses: urine free cortisol, $626 \mathrm{nmol} /$ $24 \mathrm{hr}$ ( <270); plasma cortisol, 9 a.m. $662 \mathrm{nmol} / \mathrm{l}$ ( $<500), 12$ midnight $634 \mathrm{nmol} / \mathrm{l}(<240)$; dexamethasone suppression test $8 \mathrm{mg} / \mathrm{day}$, suppressed plasma cortisol at 12 midnight to $248 \mathrm{nmol} / \mathrm{l}$. Glucose tolerance test basal, $5 \mathrm{mmol} / \mathrm{l} ; 60 \mathrm{~min}, 12 \mathrm{mmol} / \mathrm{l} ; 120$ min, $11 \mathrm{mmol} / 1$. X-rays: small pituitary tumour. A diagnosis of Cushing's disease with radiological evidence of pituitary tumour was made. He was then started on metyrapone $750 \mathrm{mg}$ thrice/day and dexamethasone $0.5 \mathrm{mg}$ twice/day and, in December 1975, was treated with external radiotherapy $4000 \mathrm{rad}$ to the pituitary fossa. During 1976 and 1977 there was no regression of his symptoms despite continuing with these drugs, and in April 1977, when re-assessed off therapy, the results were: plasma cortisol, 9 a.m. $580 \mathrm{nmol} / \mathrm{l}, 12$ midnight $331 \mathrm{nmol} / \mathrm{l}$; plasma ACTH 9 a.m. $165 \mathrm{ng} / \mathrm{l}(<80), 12$ midnight $88 \mathrm{ng} / \mathrm{l}(<10)$. Metyrapone was increased to $750 \mathrm{mg}$ 4 times/day and he was continued on the same dose of dexamethasone. However, he continued to deteriorate and developed many leg ulcers which were very slow in healing.

In January 1978 he was assessed with a view to pituitary surgery. During carotid angiography he developed apnoea and required ventilating and it was therefore decided impracticable to consider further surgical intervention of his pituitary gland. He was discharged on his previous dose of metyrapone and dexamethasone. There was still further deterioration in his condition. In September 1978 his left 5 th toe was amputated because of gangrene.

He was referred to Hammersmith Hospital in December 1978 from his local hospital. He was chair-bound, obviously Cushingoid, and had many painful ulcers in all limbs. His skin was very dry and paper-thin. There were no pulses palpable below his femorals; BP $150 / 90 \mathrm{mmHg}$. Pin-prick sensation was diminished in his feet, vibration sense was absent in his ankles and both ankle jerks were absent. There were expiratory rhonchi (he smoked 20 cigarettes/day). The right fundus showed numerous small flat new vessels, markedly tortuous veins, multiple dot and blot haemorrhages and some hard exudates at the macula (Fig. 1). Investigations 
confirmed the initial diagnosis of Cushing's disease with radiological evidence of a pituitary tumour. $\mathrm{He}$ was treated with a pituitary implant of ${ }^{80} \mathrm{Y} 150000$ rad on 23 January 1979.

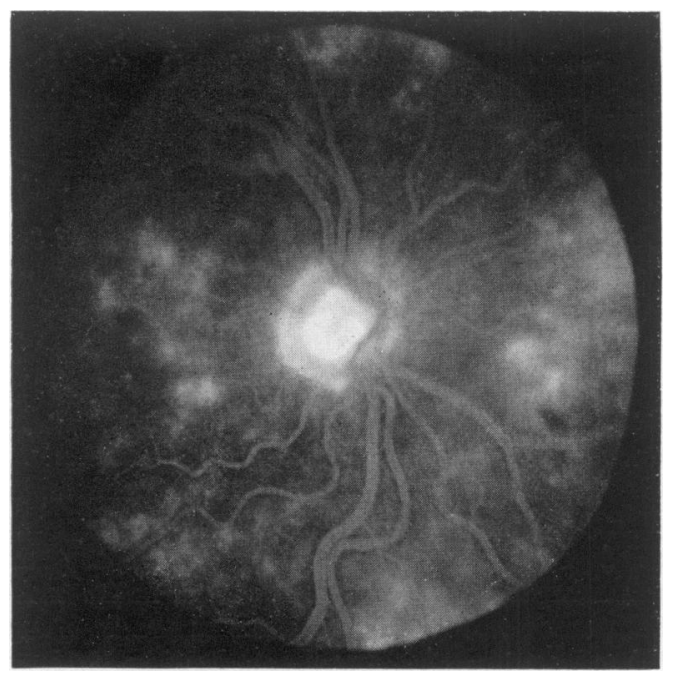

Fig. 1. Fluorescein angiogram of right macula in the late phase showing extensive leakage of dye from new vessels arising from the disc and the retinal periphery.

Postoperatively he developed a chest infection which responded to antibiotics and he had to have bilateral above-knee amputations because of sepsis in his ulcers. Over the next few weeks, the Cushinggoid features started to regress. The stumps healed.
His diabetic retinopathy did not show any significar change at 13 weeks postoperatively. After he was weaned off steroids he showed adrenocortical deficiency. Insulin hypoglycaemia test on 36 March showed a serum cortisol response $<90$ nmote throughout and he was started on prednisone. He $\frac{5}{18}$ still on prednisone $2 \mathrm{mg} /$ day. At that time plasm ACTH levels were 9 a.m. $<11.0 \mathrm{ng} / \mathrm{l}, 12$ midnig/ $<11 \mathrm{ng} / \mathrm{l}$, and a repeat glucose tolerance test gake the following results: fasting $3.4 \mathrm{mmol} / 1,120 \mathrm{~min}$ $8.4 \mathrm{mmol} / \mathrm{l}$ (peak level). The rest of his anterio pituitary function was normal.

\section{Discussion}

The possibility arises that patients usually die $\bar{\theta}$ Cushing's syndrome before they have time to develoip diabetic retinopathy, while this patient's Cushing's disease was slightly controlled by his treatments sufficient to keep him alive, and he develope diabetic retinopathy. One cannot of course exclude that he had co-incident severe diabetes mellitus, bot the marked improvement in his glucose toleranee following his remission is against this.

\section{References}

Graef, I. \& MaIER, H.C. (1962) Observations on the influence of adrenalectomy on diabetic retinopathy. Diabeteso 19 485.

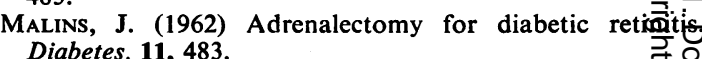

Plotz, C.A., Knowlton, A.I. \& Ragan, C. (1952) T natural history of Cushing's syndrome. American Journ of Medicine, 13, 597.

Thorn, G.W., Renold, A.E. \& Cahill, G.F. (1959) TR adrenal and diabetes. Some interactions and interrelations. Diabetes, 8, 337. 